\title{
Role of saxagliptin as monotherapy or adjunct therapy in the treatment of type 2 diabetes
}

This article was published in the following Dove Press journal:

Therapeutics and Clinical Risk Management

31 May 2010

Number of times this article has been viewed

\section{Morali D Sharma \\ Baylor College of Medicine, Houston, Texas, USA}

\begin{abstract}
Type 2 diabetes is associated with decreased incretin hormone response to an oral glucose load, and a progressive decline in postprandial glucagon-like peptide-1 (GLP-1) secretion. Incretin-based therapies offer a new option for treatment of type 2 diabetes. Saxagliptin, a potent, selective dipeptidyl peptidase-4 (DPP-4) inhibitor specifically designed for extended inhibition of the DPP-4 enzyme, causes increased endogenous GLP-1 concentration. In a phase 3 clinical trials program of 24 weeks duration, saxagliptin was studied in 6 multicenter, multinational, randomized, controlled studies and in combination with 3 of the most commonly administered oral antidiabetic drugs: metformin, glyburide and a thiozolidinedione (TZD). Saxagliptin provided significant reductions in hemoglobin $\mathrm{HbA}_{1 \mathrm{c}}$ when given with metformin, glyburide, a TZD, or as monotherapy. Saxagliptin also reduced fasting plasma glucose and 2-hour post-prandial glucose in each of these studies, and was weight and lipid neutral. Saxagliptin was well tolerated and had a low risk of hypoglycemia when used as monotherapy.
\end{abstract}

Keywords: saxagliptin, incretins, type 2 diabetes, DPP-4 inhibitors

\section{Introduction}

Type 2 diabetes is a growing epidemic worldwide for which medical treatments are still actively sought. The nationwide incidence of diabetes has nearly doubled in the last decade. In the United States 17.9 million people have been diagnosed with type 2 diabetes, and another 5.7 million remain undiagnosed. ${ }^{1}$ Three landmark prospective, interventional studies - the Diabetes Control and Complications Trial (DCCT) ${ }^{2,3}$ the Kumamoto study, ${ }^{4}$ and the United Kingdom Prospective Diabetes Study (UKPDS) ${ }^{5}$ - showed significant reductions in the incidence of microvascular complications in patients with diabetes who were treated intensively, compared with conventional treatment. The DCCT, Kumamoto study, and UKPDS provide the accepted evidence that optimal glycemic control reduces the risk of complications. Yet glycemic control rates in the US and worldwide are poor and may be on the decline. ${ }^{6}$ After adjustment for age, ethnicity, sex, body mass index (BMI), medication use, and duration of diabetes, the odds of attaining glycemic control were $21 \%$ lower in the National Health and Nutrition Examination Survey (NHANES) 1999 to 2000 than in NHANES III (1988 to 1994; odds ratio, 0.79 ). ${ }^{7}$ Only $37.0 \%$ of those surveyed in 1999-2000 had hemoglobin $\mathrm{HbA}_{1 \mathrm{c}}\left(\mathrm{HbA}_{1 \mathrm{c}}\right)$ levels of $<7.0 \%$, a proportion even smaller than the $44.3 \%$ reported for 1988 to $1994 .^{6}$ This difference, although not statistically significant, shows a trend that must be reversed. $57.1 \%$ of patients with diagnosed diabetes have an $\mathrm{HbA}_{1 \mathrm{c}}$ at or below the ADA guideline-recommended level of 7\%. ${ }^{8}$ 
The failure to achieve adequate glycemic control has led to further study of the pathogenesis of the disease and new drug discovery. We now understand that insulin demand increases in persons with increased caloric consumption, decreased physical activity, and increased age. Persons who are unable to compensate for increased insulin demand can develop prediabetes states, such as impaired glucose tolerance (IGT) and impaired fasting glucose (IFG), which can then progress to type 2 diabetes.

In patients who develop type 2 diabetes, beta-cell function appears to decline over time. Postprandial hyperglycemia develops gradually, later followed by a rise in fasting plasma glucose (FPG) levels. Hence, IGT and IFG represent intermediate steps in the progression to the clinical diagnosis of diabetes. Complications, including macrovascular and microvascular changes, begin well in advance of the clinical diagnosis of type 2 diabetes.

Incretin hormones play an important role in the regulation of blood glucose. Increased understanding of the glucoregulatory action of incretin hormones has yielded greater insight into the pathophysiology of diabetes and has led to the development of new treatments for patients with type 2 diabetes. Incretin hormone glucose-dependent insulinotropic peptide (GIP) is mainly secreted by the K cells in the duodenum and the proximal small intestine and glucagon-like peptide-1 (GLP-1) is secreted from the L cells of the distal gut. Specifically, it has been demonstrated that the endogenous human incretin hormone GLP-1 decreases blood glucose by several pathways - via the regulation of insulin and glucagon, inhibition of gastric emptying, and suppression of appetite, and that the normal physiologic response to GLP-1 is impaired in type 2 diabetes. ${ }^{9,10,11}$ GLP-1 stimulates insulin secretion in a glucose-dependent manner and suppresses glucagon secretion. ${ }^{10}$ In normal physiology, oral ingestion of nutrients stimulates GIP and GLP-1 secretion, which in turn increases insulin secretion from pancreatic beta-cells. Some studies have demonstrated a progressive decline in postprandial GLP-1 secretion, where individuals with normal glucose tolerance secrete more than those with impaired glucose tolerance, and individuals with type 2 diabetes demonstrate the greatest impairment in GLP-1 secretion. ${ }^{11}$ The clinical utility of native GLP-1 is limited by its short half-life ( $<2$ minutes) due to its rapid degradation to inactive metabolites by the enzyme dipeptidyl peptidase-4 (DPP-4).$^{10}$ Because of this limitation, new treatment approach has been developed to inhibit DPP-4 enzyme and thereby increase endogenous incretin hormone levels. They have shown a beneficial effect on beta-cell function in animal studies but there are no clinical trials to date showing preservation of beta-cell function. ${ }^{10}$

The first DPP-4 inhibitor, sitagliptin, was approved by the Food and Drug Administration (FDA) in 2006 for use as monothearpy or in combination with metformin or thiozolidinediones (TZDs). Another DPP-4 inhibitor, vildagliptin, was approved in Europe in 2008. Saxagliptin (Onglyza ${ }^{\circledR}$; Bristol-Myers Squibb) is also a potent, selective DPP-4 inhibitor specifically designed for extended inhibition of the DPP-4 enzyme causing increased endogenous GLP-1 concentration, and is now approved by the FDA.

\section{Pharmacology}

In patients with type 2 diabetes mellitus, administration of saxagliptin inhibits DPP-4 enzyme activity for a 24-hour period. The mean time to maximum concentration $\left(\mathrm{T}_{\max }\right)$ following the $5 \mathrm{mg}$ once daily dose is 2 hours for saxagliption and 4 hours for its active metabolite 5-hydroxy saxagliptin. The maximum concentration $\left(\mathrm{C}_{\max }\right)$ and area under the curve (AUC) values of saxagliptin and its active metabolite increase proportionally in the 2.5 to $400 \mathrm{mg}$ dose range. The metabolism of saxagliptin is primarily by cytochrome $\mathrm{P} 450$ 3A4/5 (CYP3A4/5). Therefore, strong CYP3A4/5 inhibitors and inducers alter the pharmacokinetics of saxagliptin and its active metabolite. Saxagliptin is excreted by both renal and hepatic pathways. $75 \%$ of saxagliptin is eliminated in the urine and $22 \%$ in the feces. Following a single oral dose of $5 \mathrm{mg}$ saxagliptin to healthy subjects, the mean plasma terminal half-life $\left(t_{1 / 2}\right)$ for saxagliptin and its active metabolite was 2.5 and 3.1 hours, respectively. ${ }^{12}$

\section{Clinical studies}

Recent American Association of Clinical Endocrinologists (AACE) treatment guidelines have included incretin-based therapies such as DPP-4 inhibitors. ${ }^{13}$ The DPP-4 inhibitors are suggested to be used in the early stage of type 2 diabetes, with a main indication in combination with metformin in subjects with inadequate glycemic control when treated with metformin alone. DPP-4 inhibition may also be used in combination with sulfonylurea and TZDs. Sitagliptin was the first DPP-4 inhibitor to be approved in the United States. As monotherapy, sitagliptin 25 to $200 \mathrm{mg} /$ day reduced $\mathrm{HBA}_{1 \mathrm{c}}$ from baseline by $-0.28 \%$ to $-0.76 \%$ at 12 to 24 weeks. ${ }^{14,15}$ As initial therapy, sitagliptin-metformin combination therapy worked better than either sitagliptin or metformin monotherapy with an $\mathrm{HbA}_{1 \mathrm{c}}$ reduction of $1.9 \%$ compared with $0.6 \%$ to $0.7 \%$, and $1.13 \%$ after 24 weeks. As adjuvant therapy, sitagliptin in combination with metformin, glipizide, 
or pioglitazone yielded an $\mathrm{HbA}_{1 \mathrm{c}}$ reduction of $0.6 \%$ to $0.7 \%$ when compared with placebo. Sitagliptin is renally eliminated and so its dose should be adjusted in patients with renal insufficiency. ${ }^{14,15}$ Vildagliptin, another DPP-4 inhibitor approved for use in Europe and under regulatory review in the United States is effective as adjuvant therapy when administered to patients inadequately controlled with sulfonylurea, metformin, $\mathrm{TZD}$, or insulin therapy with $\mathrm{HbA}_{1 \mathrm{c}}$ reduction of $0.6 \%, 0.9 \%, 1.0 \%$, and $0.5 \%$, respectively. ${ }^{16,17}$ In addition, vildagliptin and pioglitazone were equally effective as adjuvant therapy for patients who were inadequately controlled on metformin, in which $\mathrm{HbA}_{1 \mathrm{c}}$ reductions of 0.9 and $1.0 \%$ were noted, respectively. ${ }^{18}$ Vildagliptin and sitagliptin have now been examined in a large number of subjects and shown to be tolerable and safe, the overall prevalence of adverse events has been similar to that seen in placebo groups both in monotherapy and in combination therapy with metformin, sulfonylurea or TZDs. ${ }^{14-18}$

Saxagliptin was approved by the FDA in July 2009, and is indicated as an adjunct to diet and exercise to improve glycemic control in adults with type 2 diabetes mellitus. ${ }^{12}$

\section{Saxagliptin clinical trials Monotherapy trials}

In the 24-week placebo-controlled trial 401 inadequately controlled type 2 diabetes patients ( $\mathrm{HbA}_{1 \mathrm{c}} 7 \%$ to $10 \%$ ) were randomized to receive $2.5,5$ or $10 \mathrm{mg}$ saxagliptin or placebo. Results showed significant improvements in $\mathrm{HbA}_{1 \mathrm{c}}$, FPG and post-prandial glucose (PPG) in patients treated with saxagliptin compared to placebo. Saxagliptin demonstrated statistically significant decreases in adjusted mean $\mathrm{HbA}_{1 \mathrm{c}}$ changes from baseline (mean, $7.9 \%$ ) to week $24(-0.43 \%,-0.46 \%,-0.54 \%)$ for saxagliptin $2.5,5$, and $10 \mathrm{mg}$, respectively, vs $+0.19 \%$ for placebo (all $P<0.0001$ ). Adjusted mean FPG was significantly reduced from baseline $(-15,-9,-17 \mathrm{mg} / \mathrm{dL})$ for saxagliptin $2.5,5$, and $10 \mathrm{mg}$, respectively, vs $+6 \mathrm{mg} / \mathrm{dL}$ for placebo $(P=0.0002, \mathrm{p}=0.0074, P<0.0001$, respectively $)$. PPG-AUC was reduced for saxagliptin $2.5,5$, and $10 \mathrm{mg}$ $(-6868,-6896,-8084 \mathrm{mg} \times \mathrm{min} / \mathrm{dL}$, respectively) vs placebo $(-647 \mathrm{mg} \times \mathrm{min} / \mathrm{dL})$ with statistical significance demonstrated for saxagliptin $5 \mathrm{mg}(P=0.0002)$ and $10 \mathrm{mg}(P<0.0001)$. Saxagliptin was not associated with weight gain. ${ }^{19}$

\section{Combination trials}

Initial combination therapy with metformin and saxagliptin

In a phase 3 randomized, double-blind, placebo-controlled clinical trial of 1306 treatment-naïve adult patients with type 2 diabetes were evaluated over a 24-week period. Saxagliptin was coadministered with metformin in patients with inadequate glycemic control ( $\mathrm{HbA}_{1 \mathrm{c}} 8 \%$ to $12 \%$ ) on diet and exercise alone. Patients were randomized to one of 4 treatment arms: saxagliptin $5 \mathrm{mg}$ plus metformin $500 \mathrm{mg}$, saxagliptin $10 \mathrm{mg}$ plus metformin $500 \mathrm{mg}$, saxagliptin $10 \mathrm{mg}$ plus placebo, or metformin $500 \mathrm{mg}$ plus placebo. In the 3 treatment groups receiving metformin, the metformin dose was up-titrated weekly in $500 \mathrm{mg} /$ day increments, as tolerated, to a maximum of $2000 \mathrm{mg} /$ day based on FPG. Patients who failed to meet specific glycemic goals during the studies were treated with pioglitazone rescue as add-on therapy. Saxagliptin $5 \mathrm{mg}$ as initial combination therapy with metformin provided statistically significant reduction in $\mathrm{HbA}_{1 \mathrm{c}}$ vs metformin plus placebo $(-2.5 \%$ vs $-2.0 \%, P<0.0001)$ at 6 months. In this study, a higher percentage (60\%) of patients on combination therapy reached their $\mathrm{HbA}_{1 \mathrm{c}}$ goal compared to patients on metformin plus placebo $(41 \%) .{ }^{20}$

\section{Add-on studies}

In the phase 3, 24-week, randomized, placebo-controlled, double-blind clinical trial, the safety and efficacy of saxagliptin in combination with metformin was evaluated in 743 adult patients with inadequately controlled type 2 diabetes on metformin alone. Saxagliptin $2.5 \mathrm{mg}$ and $5 \mathrm{mg}$ added to metformin reduced $\mathrm{HbA}_{1 \mathrm{c}}$ by $-0.6 \%$, and $-0.7 \%$, respectively ( $P<0.0001$ vs placebo plus metformin) at 6 months Saxagliptin $5 \mathrm{mg}$ plus metformin resulted in a FPG reduction of $-22 \mathrm{mg} / \mathrm{dL}(P<0.05$ vs placebo plus metformin, $\mathrm{n}=187$, baseline FPG $179 \mathrm{mg} / \mathrm{dL}$ ) and a PPG reduction of $-58 \mathrm{mg} / \mathrm{dL}$ $(P<0.05$ vs placebo plus metformin, $\mathrm{n}=155$, baseline $\mathrm{PPG}$ $296 \mathrm{mg} / \mathrm{dL}$ ) at 6 months. ${ }^{21}$

In another add-on trial, 768 inadequately controlled diabetic patients on submaximal dose of glyburide were randomized to receive either 2.5 or $5 \mathrm{mg}$ of saxagliptin add-on to $7.5 \mathrm{mg}$ glyburide or to placebo plus a $10 \mathrm{mg}$ total daily dose of glyburide. Patients who failed to meet specific glycemic goals during the study were rescued with metformin treatment, added on to existing study medication. Compared to up-titrated glyburide, saxagliptin $5 \mathrm{mg}$ plus 7.5 mg glyburide provided statistically significant reductions in $\mathrm{HbA}_{1 \mathrm{c}}$ at 6 months $(-0.6 \% \mathrm{vs}+0.1 \%, P<0.0001) .{ }^{22} \mathrm{An}$ increase from baseline in body weight, of small magnitude and unclear clinical relevance, occurred in all treatment groups; however, weight gain was higher in the saxagliptin treatment groups. Improved glycemic control has been shown to promote weight gain in certain instances by decreasing glucosuria. ${ }^{22}$ 
Saxagliptin was also evaluated as add-on therapy with a TZD in 565 adult type 2 diabetes patients inadequately controlled on TZD alone. Patients were randomized to 2.5 or $5 \mathrm{mg}$ of saxagliptin or placebo in addition to their current dose of TZD. At 6 months, $\mathrm{HbA}_{1 \mathrm{c}}$ reduction with saxagliptin $2.5 \mathrm{mg}$ plus TZD was $-0.7 \%(P<0.05$ vs placebo plus TZD) vs placebo plus TZD, and $-0.9 \%$ with $5 \mathrm{mg}$ saxagliptin plus TZD vs placebo vs TZD $(P<0.0001){ }^{23}$

\section{Safety and tolerability}

The most common adverse reactions reported in $>5 \%$ of saxagliptin-treated patients and more commonly than in controls were upper respiratory tract infection $(7.7 \%, 7.6 \%)$, headache $(7.5 \%, 5.2 \%)$, nasopharyngitis $(6.9 \%, 4.0 \%)$ and urinary tract infection $(6.8 \%, 6.1 \%)$. Discontinuation of therapy due to adverse events occurred in 3.3\% and $1.8 \%$ of patients receiving saxagliptin and placebo, respectively. There was a dose-related mean decrease in absolute lymphocyte count observed with saxagliptin. The clinical significance of this decrease is unknown. Hypersensitivity-related events such as urticaria and facial edema in the pooled analysis up to week 24 were reported in $1.5 \%, 1.5 \%$ and $0.4 \%$ of patients who received saxagliptin $2.5 \mathrm{mg}$, saxagliptin $5 \mathrm{mg}$, and placebo, respectively. ${ }^{19,20,21}$ Analysis of pooled data also showed no significant weight gain or effect on lipid profile compared to placebo. ${ }^{19-24}$

The overall incidence of adverse events in medicationnaïve patients receiving saxagliptin $5 \mathrm{mg}$ as initial combination with metformin compared with those receiving placebo plus metformin was $55 \%$ vs 59\%, respectively. ${ }^{20}$ These adverse events included headache $(7.5 \%$ vs $5.2 \%$ with metformin plus placebo) and nasopharyngitis (6.9\% vs $4.0 \%$ with metformin plus placebo). When used as add-on combination therapy with a TZD, the incidence of peripheral edema for saxagliptin $2.5 \mathrm{mg}, 5 \mathrm{mg}$, and placebo was 3.1\%, 8.1\% and $4.3 \%$, respectively. ${ }^{23}$ The rates of peripheral edema for saxagliptin $2.5 \mathrm{mg}$ and $5 \mathrm{mg}$ vs placebo were $3.6 \%$ and $2 \%$ vs $3 \%$ when given as monotherapy, ${ }^{19} 2.1 \%$ and $2.1 \%$ vs $2.2 \%$ when given as add-on therapy to metformin, ${ }^{20}$ and $2.4 \%$ and $1.2 \%$ vs $2.2 \%$ when given as add-on therapy to glyburide. ${ }^{22}$ In the add-on to glyburide study, the incidence of reported hypoglycemia was higher in patients treated with saxagliptin $5 \mathrm{mg}$ plus glyburide (14.6\%) vs placebo plus uptitrated glyburide $(10.1 \%) .{ }^{22}$ However, the incidence of confirmed hypoglycemia in this study was $0.8 \%$ for saxagliptin $5 \mathrm{mg}$ plus glyburide and $0.7 \%$ for placebo plus up-titrated glyburide. ${ }^{22}$ The incidence of reported hypoglycemia with saxagliptin $5 \mathrm{mg}$ vs placebo as add-on therapy to a TZD was $2.7 \%$ vs $3.8 \%,{ }^{23}$ and the incidence of reported hypoglycemia with saxagliptin given as monotherapy was $5.6 \%$ compared to $4.1 \%$ for placebo. ${ }^{19}$

\section{Summary}

Management of type 2 diabetes is difficult because none of the commonly prescribed oral therapies address the progressive decline in beta-cell function. Incretin-based therapies are associated with positive effects on beta-cell function, making them a potentially beneficial therapeutic option early in the disease when patients with type 2 diabetes still maintain some degree of beta-cell function. Although there no head-to-head studies comparing the different DPP-4 inhibitors, sitagliptin, vildagliptin and saxagliptin have shown about equal efficacy of $0.4 \%$ to $0.8 \% \mathrm{HbA}_{1 \mathrm{c}}$ reduction. Saxagliptin is a potent DPP-4 inhibitor, which increases endogenous incretin levels. GLP-1 decreases glucose level by increasing insulin secretion in a glucose-dependent manner and by decreasing plasma glucagon concentrations. Thus saxagliptin may give adult type 2 patients the extra help they need in their struggle to gain glycemic control. In phase 3 clinical trials placebo-corrected $\mathrm{HbA}_{1 \mathrm{c}}$ reductions with saxagliptin $5 \mathrm{mg}$ were $-0.8 \%$ when added to metformin, $-0.7 \%$ when added to glyburide, $-0.6 \%$ when added to a TZD and $-0.6 \%$ as monotherapy at 6 months. The overall incidence of adverse events was similar between saxagliptin and placebo ( $72 \%$ vs $71 \%$, respectively). Saxagliptin is weight and lipid neutral, offers once-daily dosing, and is now approved by the United States FDA for the treatment of adults with type 2 diabetes.

\section{Disclosures}

Dr Sharma is a speaker for Bristol-Myers Squibb and AstraZeneca.

\section{References}

1. Centers for Disease Control. National Diabetes Fact Sheet, 2007. Centers for Disease Control Web site. http://www.cdc.gov/diabetes/pubs/pdf/ ndfs_2007.pdf. Accessed 2008 June 24.

2. Nathan DM, Cleary PA, Backlund JY, et al. Intensive diabetes treatment and cardiovascular disease in patients with type 1 diabetes. N Engl J Med. 2005;353:2643-2653.

3. Diabetes Control and Complications Trial Research Group. The effect of intensive treatment of diabetes on the development and progression of long-term complications in insulin-dependent diabetes mellitus. N Engl J Med. 1993;329:977-986.

4. Ohkubo Y, Kishikawa H, Araki E, et al. Intensive insulin therapy prevents the progression of diabetic microvascular complications in Japanese patients with non-insulin-dependent diabetes mellitus: a randomized prospective 6-year study. Diabetes Res Clin Pract. 1995;28:103-117.

5. United Kingdom Prospective Diabetes Study Group. Intensive bloodglucose control with sulphonylureas or insulin compared with conventional treatment and risk of complications in patients with type 2 diabetes (UKPDS 33). Lancet. 1998;352:837-853. 
6. Saydah SH, Fradkin J, Cowie CC. Poor control of risk factors for vascular disease among adults with previously diagnosed diabetes. JAMA. 2004;291:335-342.

7. Koro CE, Bowlin SJ, Bourgeois N, Fedder DO. Glycemic control from 1988 to 2000 among U.S. adults diagnosed with type 2 diabetes: a preliminary report. Diabetes Care. 2004;27:17-20.

8. Nathan DM, Buse JB, Davidson MB, et al. Medical management of hyperglycemia in type 2 diabetes: a consensus algorithm for the initiation and adjustment of therapy. A consensus statement of the American Diabetes Association and the European Association for the study of Diabetes. Diabetes Care. 2009;32:193-203.

9. Kim W, Egan JM. The role of incretins in glucose homeostasis and diabetes treatment. Phamacol Rev. 2008;60:470-512.

10. Drucker DJ. The biology of incretin hormones. Cell Metab. 2006;3: $153-165$

11. Toft-Nielsen MB, Damholt MB, Madsbad S, et al. Determinants of the impaired secretion of glucagon-like peptide-1 in type 2 diabetic patients. J Clin Endocrinol Metab. 2001;86:3717-3723.

12. Saxagliptin (Onglyza) for type 2 diabetes. Med Lett Drugs Ther. 2009;51:85-86.

13. ACE Diabetes Mellitus Clinical Practice Task Force. American Association on Clinical Endocrinologists medical guidelines for clinical practice for the management of diabetes mellitus. Endocr Pract. 2007;13 Suppl 1:3-68.

14. Hanefeld M, Herman GA, Wu M, et al. Once-daily sitagliptin, a dipeptidyl peptidase- 4 inhibitor, for the treatment of patients with type 2 diabetes. Curr Med Res Opin. 2007;23:1329-1339.

15. Raz I, Hanefeld M, Xu L, et al. Efficacy and safety of the dipeptidyl peptidase-4 inhibitor sitagliptin as monotherapy in patients with type 2 diabetes mellitus. Diabetologia. 2006;49:2564-2571.

16. Pi-Sunyer FX, Schweizer A, Mills D, et al. Efficacy and tolerability of vildagliptin monotherapy in drug-naive patients with type 2 diabetes. Diabetes Res Clin Pract. 2007;76:132-138.
17. Ristic S, Byiers S, Foley J, et al. Improved glucaemic control with dipeptidyl peptidase-4 inhibition in patients with type 2 diabetes: vildagliptin (LAF237) dose response. Diabetes Obes Metab. 2005;7:692-698.

18. Garber AJ, Schweizer A, Baron MA, et al. Vildagliptin in combination with pioglitazone improves glycemic control in patients with type 2 diabetes failing thiozolidinedione monotherapy: a randomized, placebocontrolled study. Diabetes Obes Metab. 2007;9:166-174.

19. Rosenstock J, Aguilar-Salinas C, Klein E, et al. CV181-011 Study Investigators. Effect of saxagliptin monotherapy in treatment-naïve patients with type 2 diabetes. Curr Med Res Opin. 2009;25:2401-2411.

20. Jadzinsky M, Pfutzner A, Paz-Pacheco E, et al; for the CV181-039 Investigators. Saxagliptin given in combination with metformin as initial therapy improves glycaemic control in patients with type 2 diabetes compared with either monotherapy: a randomized controlled trial. Diabetes Obes Metab. 2009;11:611-622.

21. DeFronzo RA, Hissa NM, Garber AJ, et al. The efficacy and safety of saxagliptin when added to metformin therapy in patients with inadequately controlled type 2 diabetes with metformin alone. Diabetes Care. 2009;32:1649-1655.

22. Chacra AR, Tan GH, Apanovitch A, et al. CV181-040 Investigators. Saxagliptin added to a submaximal dose of sulfonylurea improves glycaemic control compared with uptitration of sulfonylurea in patients with type 2 diabetes: a randomized controlled trial. Int J Clin Pract. 2009;63:1395-1406.

23. Hollander P, Li J, Allen E, Chen R; CV181-013 Investigators. Saxagliptin added to a thiazolidinedione improves glycemic control in patients with type 2 diabetes and inadequate control on thiazolidinedione alone. J Clin Endocrinol Metab. 2009;94:4810-4819.

24. Rosenstock J, Sankoh S, List JF. Glucose-lowering activity of the dipeptidyl peptidase-4 inhibitor saxagliptin in drug-naive patients with type 2 diabetes. Diabetes Obes Metab. 2008;10:376-386.
Therapeutics and Clinical Risk Management

\section{Publish your work in this journal}

Therapeutics and Clinical Risk Management is an international, peerreviewed journal of clinical therapeutics and risk management, focusing on concise rapid reporting of clinical studies in all therapeutic areas, outcomes, safety, and programs for the effective, safe, and sustained use of medicines. This journal is indexed on PubMed Central, CAS,

\section{Dovepress}

EMBase, Scopus and the Elsevier Bibliographic databases. The manuscript management system is completely online and includes a very quick and fair peer-review system, which is all easy to use. Visit http://www.dovepress.com/testimonials.php to read real quotes from published authors. 